\title{
Improvement of Software Engineering Performances An Experience Report at Bombardier Transportation - Total Transit Systems Signalling Group
}

\author{
Claude Y. Laporte* \\ Mikel Doucet** \\ Claude.Y.Laporte@etsmtl.ca \\ +1-514 396-8956 \\ Denis Roy*** \\ Denis.Roy@crim.ca \\ $+1-514840-1232$
Mikel.Doucet@ca.transport.bombardier.com
+1-450 441-2020 \\ Marc Drolet \\ Marc.Drolet@us.transport.bombardier.com \\ +1-412 655-5918 \\ * Department of Software and IT Engineering \\ École de technologie supérieure \\ 1100, rue Notre-Dame Ouest, Montréal, Québec, Canada, H3C 1 K3. \\ ** Center of Competence Software Engineering \\ Bombardier Transportation \\ 1101, rue Parent, St-Bruno, Québec, Canada, J3V 6E6 \\ *** Centre de Recherche Informatique de Montréal \\ 550, rue Sherbrooke Ouest, Bureau 100 \\ Montréal, Québec, Canada, H3A 1 B9 \\ **** Total Transit Systems Signalling \\ Bombardier Transportation \\ 1200 Lebanon Road, West Mifflin, Pennsylvania, USA, 15122 \\ Copyright @ 2007 by C. Y. Laporte, M. Doucet, D. Roy \& M. Drolet. Published and used by INCOSE with permission.
}

\section{Abstract}

The performance of the Bombardier TTS/Pittsburgh Signalling group has been evaluated twice: first in November 2003 and again in January 2006. The 2003 evaluation established a baseline for the evaluation of progress made in 2006. During those visits, the same evaluation method was used to evaluate project performance and organizational change management, i.e. the people issues. Since 2003, there has been substantial improvement in both process maturity level and process performance. This experience report, at Bombardier Transportation, illustrates that process performance improvements are achievable when two key factors are involved, namely: a link between business goals and process improvement activities, and a sponsor committing the right level of resources to the improvement program. This paper explains the multi-dimensional methodology used to perform the evaluations, as well as the business goals and the quantitative performance improvements achieved since 2003. 
Proceedings - 17th Annual International Symposium, International Council on Systems Engineering, San Diego, June 24-28 2007.

\section{Introduction}

This paper presents the evaluations of process performances that have been conducted in a major transportation company. In the first section, we explain the challenges facing train manufacturers; next, we briefly describe the context of the experience report. The three dimensions of the evaluation methodology are explained. The results of the evaluations conducted in 2003 and 2006 are presented, as well as the impact of process improvements on business results. Finally, we list a series of recommendations to further improve the performance of the organization.

\section{Challenges Facing Train Manufacturers}

Since the beginning of the $20^{\text {th }}$ Century, moving people within cities and developed areas has been a technological challenge, and it is one that has necessitated the development of mass transit systems ranging from the very basic to the highly complex. There are many types of mass transit systems, six of which are described in the table 1.

\begin{tabular}{|l|c|}
\hline \multicolumn{1}{|c|}{ Type of System } & $\begin{array}{c}\text { System Capacity } \\
\text { (passengers per hour per } \\
\text { direction [pphpd]) }\end{array}$ \\
\hline $\begin{array}{l}\text { Light rail systems, which normally do not have } \\
\text { a dedicated guideway or protected guideway, } \\
\text { and which require a driver. }\end{array}$ & fewer than 5,000 \\
\hline $\begin{array}{l}\text { Metro (light Metro) and rapid transit systems, } \\
\text { which can be above ground, elevated or } \\
\text { underground, and which can adopt different } \\
\text { modes of operation ranging from manual to } \\
\text { automated. }\end{array}$ & 15,000 pphpd \\
\hline $\begin{array}{l}\text { Monorail systems, which can adopt different } \\
\text { modes of operation. }\end{array}$ & $5,000-10,000$ pphpd \\
\hline $\begin{array}{l}\text { Automated People Movers (APMs), which are } \\
\text { normally smaller types of metro mass transit } \\
\text { system that are often fully automated. }\end{array}$ & $5,000-15,000$ pphpd \\
\hline $\begin{array}{l}\text { Advanced Rapid Transit (ART) systems, } \\
\text { which feature fully automated operation. }\end{array}$ & $10,000-30,000$ pphpd \\
\hline $\begin{array}{l}\text { Heavy Metro systems, which can be automated } \\
\text { and are normally high-capacity. }\end{array}$ & $30,000-60,000$ pphpd \\
\hline
\end{tabular}

Table 1 - Types of mass transit system (adapted from Drolet 2004)

Many airport and transportation operating authorities are considering adopting the so-called unattended or driverless automation technology. Among the motivators for this are increased system efficiency and reliability, improved flexibility to respond to changing passenger volumes and reduced cost of operations over the period of the system life cycle. The advantages of automated systems are listed in table 2. 
Proceedings - 17th Annual International Symposium, International Council on Systems Engineering, San Diego, June 24-28 2007.

\begin{tabular}{|l|}
\hline Reliability and punctuality \\
\hline Train crews available for service to passengers \\
\hline Greater safety for passengers \\
\hline Shorter service intervals - less waiting for passengers \\
\hline Flexible train service for peak hours or special events \\
\hline Fewer vehicles, thus lower investment \\
\hline $\begin{array}{l}\text { Energy savings due to optimum operation, shorter platform } \\
\text { requirements }\end{array}$ \\
\hline Attractive service, thus more passengers \\
\hline
\end{tabular}

Table 2 - Advantages of automated systems (adapted from Drolet 2004)

When full automation of the transit system is the ultimate objective, it is necessary to consider a more comprehensive integration of all the elements and functions involved in the global system. With a manual system, it is possible to consider the following aspects of the system separately: vehicles and stations, the mechanical, electrical, communications, surveillance and information systems, and other functions. Automation demands that these be brought into a fully integrated system (see Figure 1). In this figure, the Wayside on the right is performing the operation and maintenance activities. This obviously increases the level of complexity, as well as the work requirements for design, testing and system validation, and to address safety considerations.

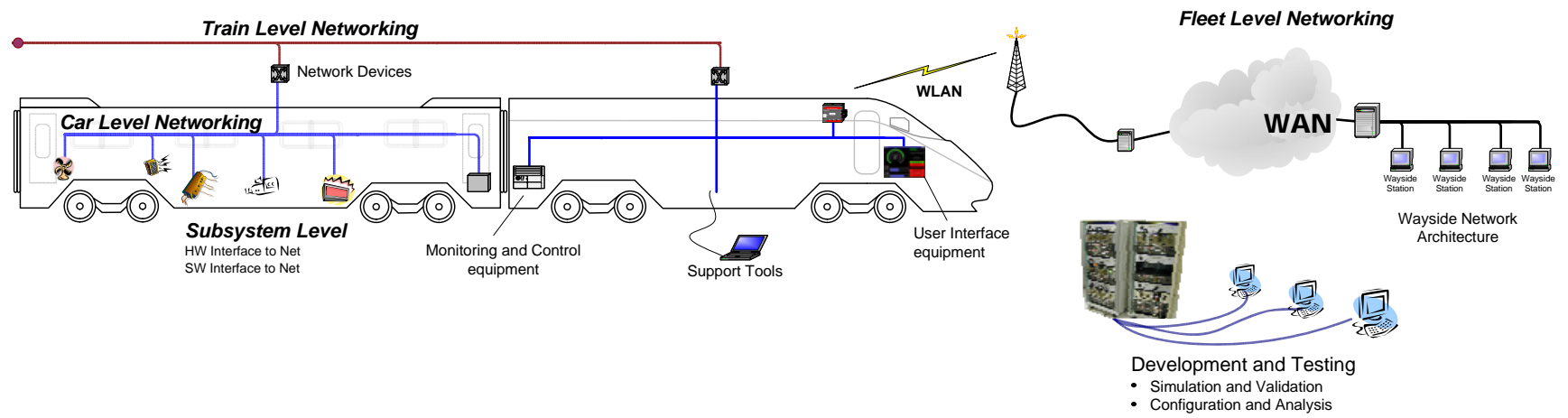

Figure 1 - Illustration of the architecture of a modern train system

For a typical transit system, it would not be uncommon to schedule over 5,000 engineering activities in the detailed project schedule for delivery of an Automatic Train Control System (ATC), nor would it be abnormal to invest well over 200,000 hours of engineering to deliver an automated system, as opposed to a fraction of this for a manual system. The complexity resides in the level of safety verification and the software needed to address all the functions particular to a driverless system.

\section{Description of the Context}

Bombardier Transportation, which was created in 1974 to provide subway wagons for the Montreal Transit Authority, grew through many acquisitions to become a leading manufacturer of rail material for moving people. The company had 16,000 employees before acquiring ADtranZ in 2001, an acquisition that brought the company 20,000 additional employees with an engineering presence in 25 countries. It is interesting to note that ADtranZ had also been the result of a merger, in that case of sections of ABB and Daimler Chrysler. Bombardier Transportation now has more than 30 software engineering sites, bringing the number of people employed in software engineering-related jobs to a total of around 950. 
Proceedings - 17th Annual International Symposium, International Council on Systems Engineering, San Diego, June 24-28 2007.

The Total Transit Systems (TTS) Division offers transportation solutions for urban and airport applications. The TTS portfolio of products includes fully automated advanced rapid transit, people mover and monorail systems, as well as guided light transit, light rapid transit and metro systems. More specifically, the Pittsburgh (Pennsylvania, USA) site of this division is mandated to develop and manufacture people mover systems. Around 100 software engineers work at this site and at the Signalling area, with some 30 additional people at the Bombardier Transport Engineering Center in India site in Hyderabad.

\section{Software Engineering Centre of Competence (CoC SWE)}

Bombardier Transportation has established a Centre of Competence (CoC) to support the various divisions in reducing technical risks and quality deficiency costs, and in continuously improving the reliability of BT products. Of interest in connection with this study is the fact that the CoC SWE, located near Montreal, is looking at the intelligence inside the trains, as information and control technologies are moving into the railway world and having a major impact on product design, manufacturing and operation (Intelligent Trains with data exchange networks, for example). The major role of this $\mathrm{CoC}$ is to bridge the gap between increasing demands on new functionalities and cost reduction, while at the same time increasing the maturity level of Bombardier's software engineering capacity.

The following constitute the mandate of the CoC:

- Support world-wide utilization of engineering experts and tools

- Support projects to help meet the schedule

- Ensure product performance through Technical Risk Analysis and Risk Mitigation

- Support standardization and modularization

- Support total cost reduction

- Ensure technical competitiveness both today and in the future

- Generate a culture of openness and willingness to share and support

In order to provide technologies to all divisions, and to do so at a rapid pace, it has been decided that a common vocabulary, common processes and common roles will be used. The strategy developed to achieve this is as follows:

- Adopt internationally recognized reference documents

o Models

o Standards

o Body of Knowledge

- Develop common processes, work instructions and role definitions o Independent of the organizational structure

So far, the CoC has led the development of integrated software engineering processes (BES), a set of software engineering Roles and Responsibilities (Bourque 2004, Laporte 2005), a set of Peer Reviews ranging from informal desk check reviews, to walkthroughs and inspections (IEEE 1028).

\section{Evaluations of the Pittsburgh TTS-Signalling Division}

At the request of the vice-president of the TTS/Pittsburgh Signalling group, the software engineering processes and their performances have been evaluated twice: first in November 2003 and again in January 2006. The 2003 evaluation established a baseline for the evaluation of progress made in 2006. 
Proceedings - 17th Annual International Symposium, International Council on Systems Engineering, San Diego, June 24-28 2007.

In the next sections, the three dimensions of the Evaluation Methodology (e.g. Process, Technology and Engineering (People)) are presented, along with the results of both evaluations (see Figure 2). As illustrated in this figure, the three dimensions are used to support business objectives (e.g. Business Context).

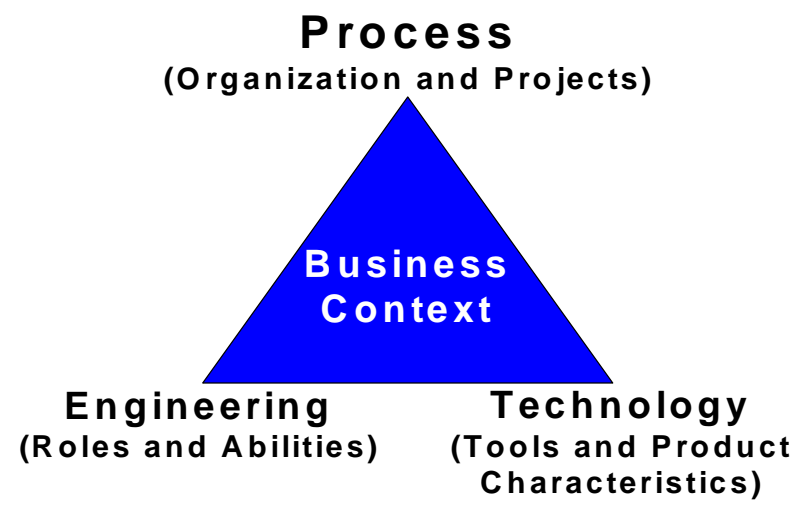

Figure 2 - The three dimensions of the Evaluation Methodology

\section{Evaluation of the Process Dimension}

The Process dimension reuses a tailored version of the industry-proven Capability Maturity Model $(\mathrm{CMM})^{1}$ evaluation methods. Depending on business needs (organizational and project list) and the scope of the evaluation, the Process Areas, or Key Process Areas (KPA) for the Software Capability Maturity Model (SW-CMM), are prioritized (high/medium/low). Then, an evaluation agenda is created using Bombardier SWE Process role names. The agenda is then updated with the individuals involved in the project who are associated with those roles. Communication is conducted in advance to ensure smooth participation and to manage the people's expectations. During the Collecting Evidence step, an Evaluation Sheet is used to log the gathered/analyzed data. This Evaluation Sheet is also used to establish the maturity indicators employed in the Site Findings.

- A- Preparation Phase

- Establishment of organizational scope

- Visit preparation (agenda)

- Information gathering [extended version only]

- Team build-up

- B- On-Site Phase

- Opening presentation

- Collection of evidence (interviews, documentation reviews)

- Documentation of the findings (strengths and weaknesses)

- Site debriefing with management representatives

- C- Reporting Phase

- Prepare Site Findings and Recommendations report

- $\quad$ Prepare Interim and Final reports

\footnotetext{
${ }^{1}$ CMM and Capability Maturity Model are registered with the U.S. Patent and Trademark Office. CMM Integration and CMMI are service marks of Carnegie Mellon University.
} 
Proceedings - 17th Annual International Symposium, International Council on Systems Engineering, San Diego, June 24-28 2007.

\section{Results of the 2003 Process Evaluation}

Process maturity was evaluated using the Software $\mathrm{CMM}^{\circledR}$ from the Software Engineering Institute (SEI) as a framework. Table 3 lists the conclusions of the CMM mini-evaluation carried out. It was found that the organization had some adjustments to make before conducting a formal SEI evaluation.

\begin{tabular}{|c|}
\hline KPAs satisfied \\
- Requirements Management \\
- Software Configuration Management \\
- Software Quality Assurance \\
KPAs partially satisfied \\
- Project Planning \\
- Project Tracking and Oversight \\
- Software Subcontractor Management
\end{tabular}

Table 3 - Results of the 2003 CMM KPA mini-evaluation

Strengths noted during this evaluation:

- $\quad$ Pride in work (dedication)

- Knowledgeable and capable software engineering professionals

- Willingness of people to work with others

- Professional attitude exhibited by staff

- Strong desire across the organization to produce quality products

A formal CMM assessment was conducted in 2005 which resulted in the group being evaluated at CMM Level 3. This is only the second of the 30 software development sites at Bombardier, with a total of 950 software engineers, which has been assessed as CMM level 3. The first site, located in Canada (St-Bruno), was evaluated in 2002. For this reason, the Process dimension was not analyzed during the 2006 evaluation.

\section{Evaluation of the Performance Measures Dimension}

Performance measures are mandatory if the contribution of the process to the achievement of business goals is to be correctly assessed. The first step was to identify the performance measures in use in the organization. Then, the methods and values were validated for applicability, validity and correctness. Finally, the results were used to evaluate the performance dimension. The elements considered during the evaluation are described below.

\section{Defects}

The objective is to measure the quality of the software developed.

- Number of defects

\section{Productivity}

The objective of the productivity index (PI) is to measure both the productivity and the productivity improvement over time, and to use the results as a basis for estimation.

- Product size (e.g. Source Line of Code)

- Effort in hours of labour

- Calculation: Product size/Effort 
Proceedings - 17th Annual International Symposium, International Council on Systems Engineering, San Diego, June 24-28 2007.

\section{Earned Value}

Earned Value Management is a method for integrating scope, schedule and resources, as well as for measuring project performance. It compares the amount of work that was planned with how much value was actually earned and with how much work was actually expended, to determine if cost and schedule performance are proceeding as anticipated. (ANSI/EIA-748-1998).

- $\quad$ Budget cost of work scheduled (BCWS)

- Budget cost of work performed (BCWP)

- Actual cost of work performed (ACWP)

- Budget at completion (BAC)

- Estimated duration

- Actual duration at completion

- Total allocated budget (TAB)

- Estimate at completion (EAC)

The Earned Value concept is illustrated in Figure 3.

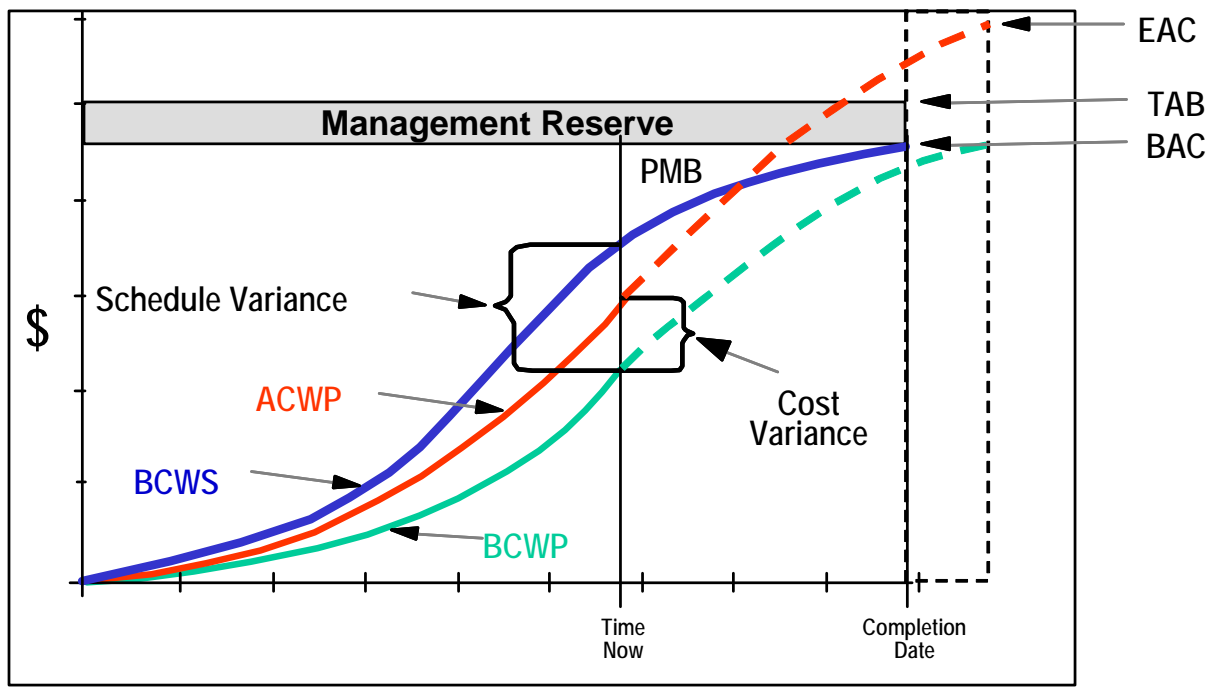

Figure 3 - Earned Value illustrated

\section{Primary measures:}

Schedule performance index (SPI)

The objective is to measure performance and take action to realign the project schedule if needed.

\section{Calculation: BCWP/BCWS}

Cost performance index (CPI)

The objective is to measure performance and take corrective action when required, as well as to compare performance with that of past projects.

Calculation: BCWP/ACWP

Critical ratio (CR) 
Proceedings - 17th Annual International Symposium, International Council on Systems Engineering, San Diego, June 24-28 2007.

\section{Calculation: SPI X CPI}

The objective, for ongoing projects, is to measure overall performance.

- $0.9>$ Ratio $<1.2$ means that the project is under control.

- $0.8>$ Ratio $<0.9$ or $1.2>$ Ratio $<1.3$ means that corrective action is required.

- $0.8>$ Ratio $>1.3$ means that the scope and estimates of the remaining project should be revised.

\subsection{Results of the 2003 Process Performance Measure Evaluation}

At the time of the 2003 evaluation, it was very difficult and time-consuming to obtain the data elements required to perform basic performance analysis. Different groups, individuals and systems had to be consulted, and the level of confidence in data accuracy was not very high. Therefore, even though the analysis results, as illustrated in Table 4, were quite good, they do not really reflect project realities.

\begin{tabular}{|l|c|c|c|}
\hline PROJECT & CPI & SPI & CR \\
\hline Project A & .72 & .97 & .7 \\
\hline Project B & .93 & .86 & .8 \\
\hline Project C & 1.0 & 1.0 & 1.0 \\
\hline
\end{tabular}

Table 4 - Results of the November 2003 Process performance evaluation

By 2003, a project management process had been defined; however, it had not really been implemented, supported or enforced. Although the process complied with SEI CMM requirements, it did not address the performance management concerns to the level required by a well-organized Earned Value Management system. Moreover, the required data collection activity was more or less considered a waste of time by a large proportion of the organization. Therefore, no real benefits were associated with, and generated by, this process.

\subsection{Results of the 2006 Process Performance Measure Evaluation}

In 2006, with a system in place, data collection was fast and easy, and the performance measures had already been calculated and used for all projects selected for the assessment. Some verification was conducted (spot checks, for example) to validate accuracy, and no discrepancies were found.

The only data element that was not readily available was product size, which prevented calculation of the Performance Index. This can be explained by the fact that numerous different engineering approaches and programming languages are in use. However, a common product sizing reference project is planned for the coming years.

As illustrated in Table 5, the analysis results now show problems and reflect project realities. This, combined with the fact that the entire organization understands and makes use of these metrics to identify the required correctives actions, constitutes a major achievement and contributes to the overall success of the organization. 
Proceedings - 17th Annual International Symposium, International Council on Systems Engineering, San Diego, June 24-28 2007.

\begin{tabular}{|l|c|c|c|}
\hline PROJECT & CPI & SPI & CR \\
\hline Project D & .88 & .67 & .59 \\
\hline Project E & 1.22 & .96 & 1.17 \\
\hline Project C & .93 & 1.01 & .94 \\
\hline Project F & 1.04 & .75 & .78 \\
\hline
\end{tabular}

Table 5 - Results of the 2006 Process Performance Evaluation

The software project tracking and oversight process has been evaluated as fully compliant with CMM requirements, and a performance management system has been implemented for it that is fully supported by an automated tool. Moreover, the commitment to the process is such that management actively participates in it and strongly enforces it. Being closely and officially associated with the organization's business objectives, the performance management system and the overall software/systems engineering process are now recognized as valuable when used in this way by the organization, and real benefits are now being generated by this process.

These measures are now meaningful to the organization and used to better manage operations in order to reach defined business goals. However, it is not clear that everyone involved has the necessary knowledge and expertise to effectively use the data and measures to contribute to the performance improvement effort.

In 2006, all the data and measures were produced regularly and for every project conducted by the organization. All the information has been made available electronically to managers by a Project Management Office (PMO) and also published on a public board called “The Wall”. All employees can therefore see the performance of all projects. The Wall displays the following elements (see Figure 4):

- $\quad$ Project Status Overview (using indicators)

- Project Risks and Issues

- Project high-level Schedule

- Other key Project Metrics

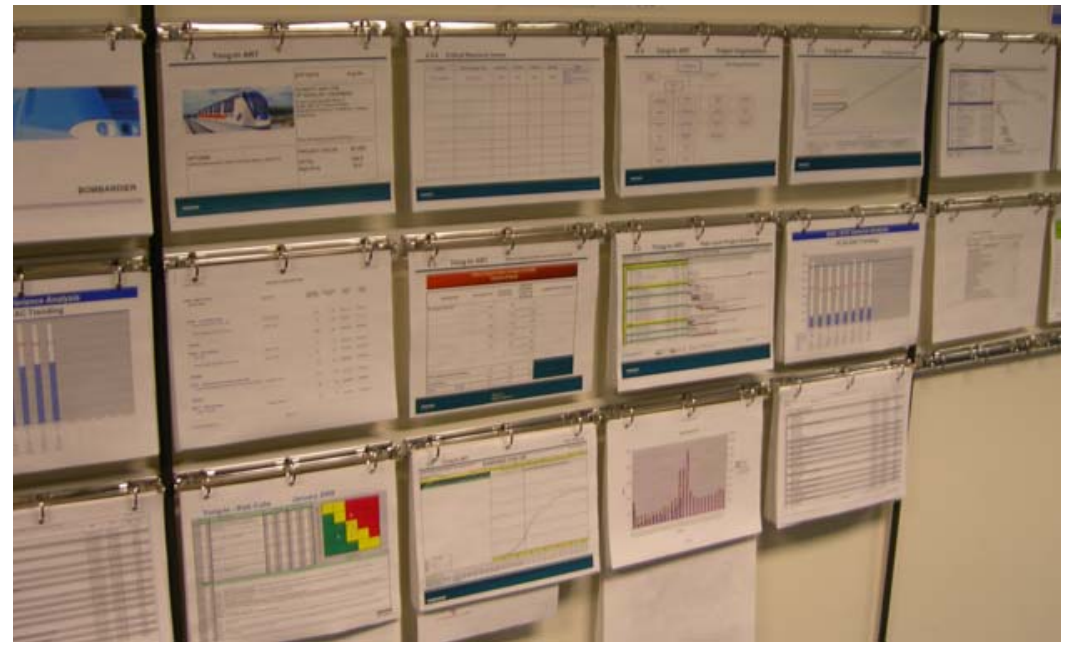

Figure 4 - "The Wall” project control board 
Proceedings - 17th Annual International Symposium, International Council on Systems Engineering, San Diego, June 24-28 2007.

\section{Evaluation of the People Dimension}

Since the management of change is a key element of a successful process improvement program, a series of actions was planned to facilitate the development, implementation and adoption of the processes, methods and tools (Laporte 1993, Laporte 1998, Laporte 1999). As illustrated in Figure 5, this structured approach was used to evaluate and manage the human and cultural elements of an organization in order to manage the changes necessary to meet its business objectives.

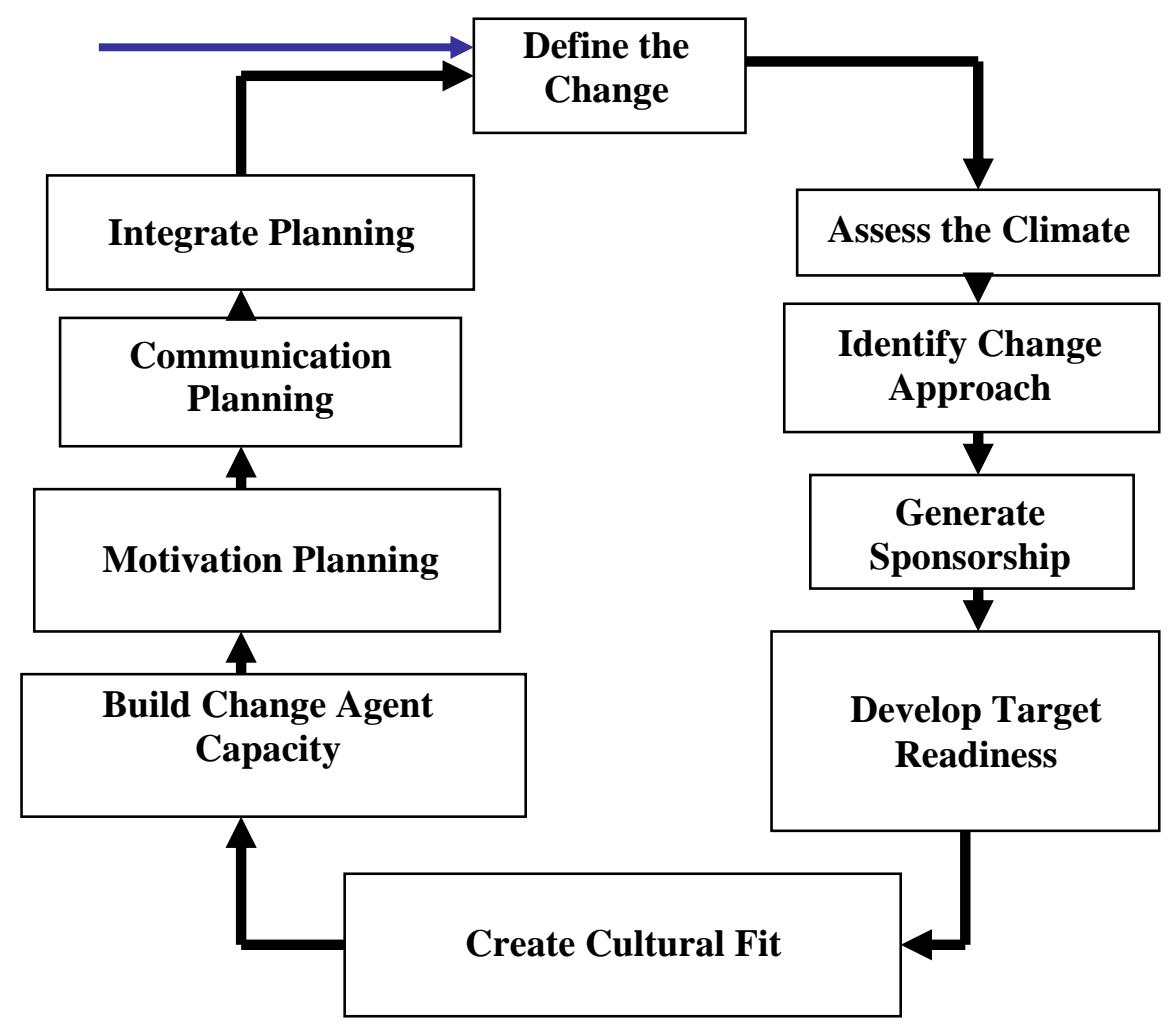

Figure 5 - Change management approach (adapted from IMA Inc.)

The organization's change readiness was evaluated, using Implementation Management Associates (IMA, www.imaworldwide.com) tools, by measuring the elements listed in Table 6.

\begin{tabular}{|l|l|}
\hline $\begin{array}{l}\text { Organization's stress } \\
\text { level }\end{array}$ & Evaluation of the priorities for resources in the organization \\
\hline Sponsor assessment & $\begin{array}{l}\text { Evaluation of the resources, reinforcement (e.g. motivation) and } \\
\text { communications commitments made and demonstrated by the sponsor(s) } \\
\text { of a change project }\end{array}$ \\
\hline Change agent skills & $\begin{array}{l}\text { Evaluation of the skills and motivation of those responsible for } \\
\text { facilitating the implementation of organizational changes }\end{array}$ \\
\hline Individual readiness & $\begin{array}{l}\text { Evaluation of the reasons why people may resist an organizational } \\
\text { change }\end{array}$ \\
\hline Culture assessment & $\begin{array}{l}\text { Assessment of the fit between the desired change and the actual } \\
\text { organizational culture in order to identify potential barriers and to } \\
\text { leverage actual cultural strengths }\end{array}$ \\
\hline
\end{tabular}


Proceedings - 17th Annual International Symposium, International Council on Systems Engineering, San Diego, June 24-28 2007.

Implementation history

Assessment of barriers and lessons learned from previous change projects (since past problems are likely to recur, this tool allows identification of the issues that need to be managed for the change project to be successful)

\section{Table 6 - Elements measured with the IMA Tools}

The assessments performed allowed the organization to better identify potential barriers and perform mitigating actions to increase the likelihood of the success of a change project.

\subsection{Results of the 2003 People Evaluation}

At the end of the opening session, questionnaires were distributed randomly to a few participants. The results of the questionnaires, as illustrated in Table 7, are useful to pinpoint weaknesses; they are not statistically valid, however, since only 19 questionnaires were completed.

- Implementation History Assessment (5 questionnaires completed):

o The scores range between 55 and 88. The average score is 62 , which indicates a low to moderate probability of implementation success. The following weaknesses were highlighted:

- Changes are not clearly prioritized;

- The focus is on too many key changes;

- Resources and rewards are not aligned with priorities;

- The focus is not maintained, and other changes are found to be distracting;

- Changes are not clearly related to key organizational vision and strategies.

- Organizational Change Stress Test (5 questionnaires completed):

0 The following changes were identified by the participants as major organizational changes:

- Productization

- Six-sigma implementation

- Bombardier-ADtranZ acquisition

- Internal split between divisions

- New process implementation (e.g. PAL)

- Organizational structure

- Move from department- to project-oriented organization

o The scores range between 340 and 1280 . The average score is 752 . A score over 600 indicates that the employees are operating in an environment of intense turbulence and complexity. Careful prioritization and allocation of resources will be critical for successful implementation of future changes.

- Individual Readiness Assessment (4 questionnaires completed):

o The scores range between 63 and 80 . The average score is 70, which indicates a moderate probability of implementation success. The following weaknesses were highlighted:

- The proposed change will not have a positive impact on job characteristics like status and/or salary;

- Past implementations have not been consistently successful;

- Work pressure and stress are significant;

- The proposed change is perceived as reversible.

- Cultural Assessment (5 questionnaires completed): 
Proceedings - 17th Annual International Symposium, International Council on Systems Engineering, San Diego, June 24-28 2007.

o The scores range between 29 and 64. The average score is 54, which indicates a low probability of implementation success. The following weakness was highlighted:

- The current reinforcement management requires a significant change.

\begin{tabular}{|l|c|c|}
\hline \multicolumn{1}{|c|}{ Assessment Tool } & Ideal Score & 2003 Score \\
\hline Implementation History & 100 & 62 \\
\hline Change Agents & 100 & Not evaluated \\
\hline Individual Readiness & 100 & 70 \\
\hline Organizational Culture & 100 & 54 \\
\hline Organizational Stress & Below 200 & 752 \\
\hline Sponsorship & 100 & Not evaluated \\
\hline
\end{tabular}

Table 7 - Results of the 2003 people evaluation

\section{Other Issues}

The following issues were captured during interviews:

- The organization has been trying for many years to attain CMM Level 2, and has been over-exposed (e.g. "bad taste") to the CMM.

- If software development moves off-shore (e.g. to India), developers will be doing the "boring” part (e.g. documenting specifications) and sending away the "interesting” part (i.e. development, coding).

- Some people do not understand the motivation behind obtaining CMMI Level 3 by 2006.

- Customers are becoming more educated and demanding.

- There are two software cultures at the Pittsburgh site: one for the development of "vital" software components and another for the development of all the other software components.

- There is a rumour about another downsizing to take place within the next few months

o From 750 employees to 500.

\section{Recommended Actions to Improve the Probability of Implementation Success}

Table 8 lists the actions recommended by the evaluation team.

\begin{tabular}{|c|c|}
\hline \multicolumn{2}{|c|}{ Communication } \\
\hline 0 & Business reasons for moving from SW-CMM to CMMI \\
\hline 0 & Business reasons for obtaining CMMI Level 3 certification by 2006 \\
\hline 0 & Rumours of downsizing \\
\hline 0 & Anticipation of off-shoring (e.g. to India) \\
\hline \multicolumn{2}{|c|}{ Framework for further process improvement } \\
\hline 0 & CENELEC (Comité Européen de Normalisation Electrotechnique) \\
\hline 0 & Certification (e.g. EN 50128) \\
\hline 0 & Objective of CMMI Level 3 by the end of 2006 \\
\hline
\end{tabular}


Proceedings - 17th Annual International Symposium, International Council on Systems Engineering, San Diego, June 24-28 2007.

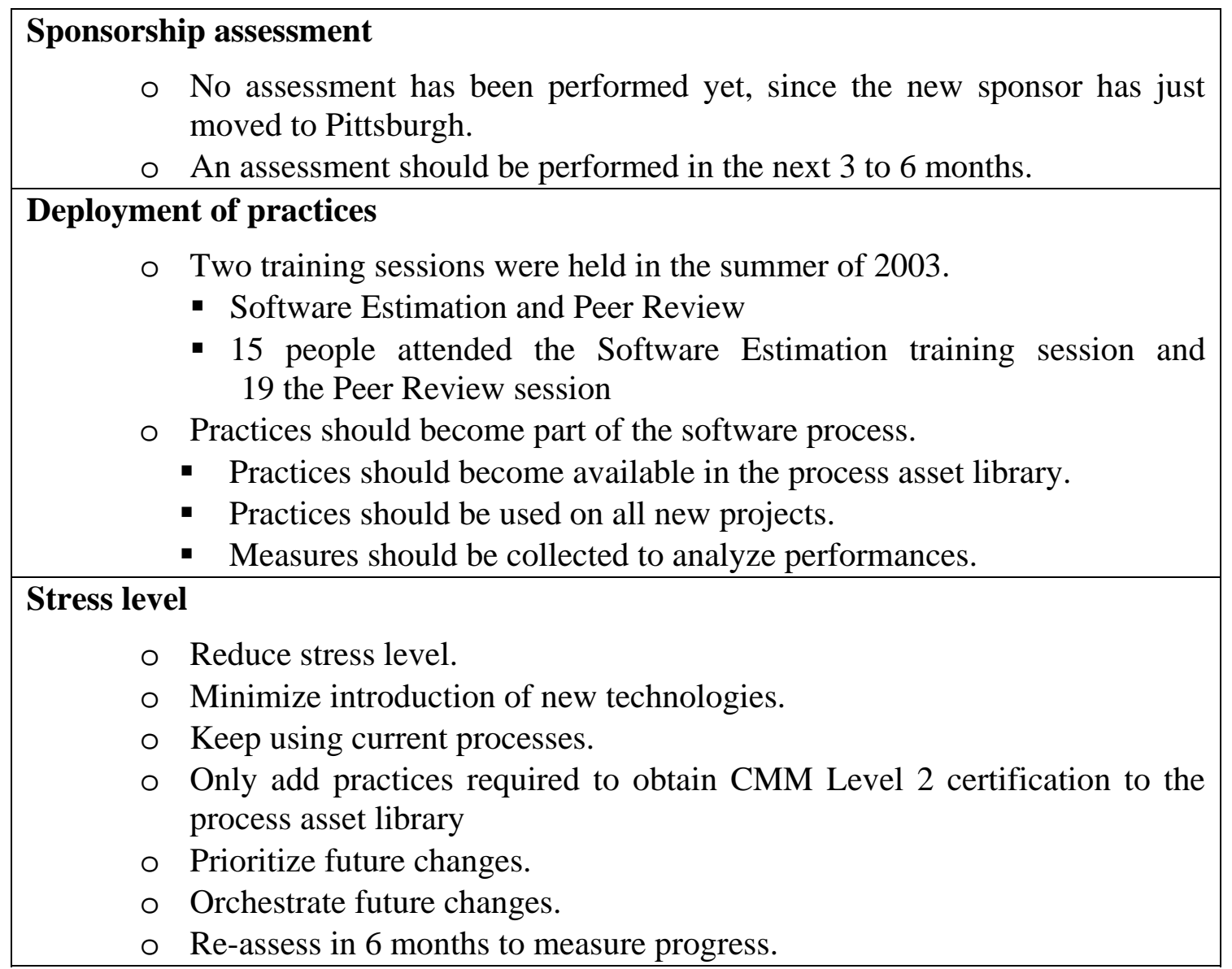

\section{Table 8 - List of proposed action items}

\subsection{Results of the 2006 People Evaluation}

During the 2006 evaluation, 21 Questionnaires were completed. As illustrated in Table 9, there have been no significant changes since the 2003 evaluation in the following areas: Implementation History, Individual Readiness. There is a slight improvement in the Organizational Culture and Organizational Stress areas, although the stress level is still quite high. While the Sponsorship level was not evaluated in 2003, the 2006 results are quite impressive. There is no doubt that such a level of sponsorship was critical to the progress made since 2003. 
Proceedings - 17th Annual International Symposium, International Council on Systems Engineering, San Diego, June 24-28 2007.

\begin{tabular}{|l|c|c|c|}
\hline \multicolumn{1}{|c|}{ Assessment Tool } & $\begin{array}{c}\text { Ideal } \\
\text { Score }\end{array}$ & 2003 Score & 2006 Score \\
\hline Implementation History & 100 & 62 & 64 \\
\hline Change Agents & 100 & Not evaluated & 66 \\
\hline Individual Readiness & 100 & 70 & 68 \\
\hline Organizational Culture & 100 & 54 & 65 \\
\hline Organizational Stress & Below 200 & 752 & 700 \\
\hline Sponsorship & 100 & Not evaluated & 90 \\
\hline
\end{tabular}

Table 9 - Results of the 2003 and 2006 evaluations

\section{Improvement of Business Indicators}

The investments made since 2003 in Process, Engineering (People) and Technology produced substantial improvements in the business indicators. As illustrated in Table 10, these include growth in revenues of $84 \%$, growth in productivity of $36 \%$ and growth in profitability of $104 \%$. Finally, the number of employees has increased since 2003, by 34\%. If we include the 32 full-time employees at BTECI (India), this represents an increase of $66 \%$.

\begin{tabular}{|l|c|c|c|}
\hline Business Indicators & $\mathbf{2 0 0 3}$ & $\mathbf{2 0 0 6}$ & Delta \\
\hline Revenue & $19.6 \mathrm{M}$ US\$ & $35.9 \mathrm{M}$ US\$ & $+84 \%$ \\
\hline Productivity & $194 \mathrm{~K}$ US\$ & 264K US\$ & $+36 \%$ \\
\hline Profitability & $2.7 \mathrm{M}$ US\$ & $5.5 \mathrm{M}$ US\$ & $+104 \%$ \\
\hline Head count (employees) & 101 & 136 & $+34 \%$ \\
& & $136+32$ (India) & $+66 \%$ \\
\hline
\end{tabular}

Table 10 - Improvement in business indicators

\section{Issues and Recommendations from the 2006 Evaluation}

During the 2006 site evaluations, a few deficiencies were noted. These issues are explained below, and recommendations are proposed.

\section{Deploy a sizing evaluation approach}

A potential area for improvement is the full implementation, as soon as possible, of the common sizing approach used in the estimation process. We agree that the SLOC (Source Lines of Code) measure may not always be appropriate; however, a common sizing measure is required to evaluate and compare the PI, which can be used later to better estimate the effort required for new projects, thereby improving predictability and profitability on new project.

\section{Embed lessons learned in organizational processes}

Lessons learned are actually captured and stored on the Intranet, so that managers can consult them when needed. Unfortunately, they are often not used by other projects. In order to make sure that these lessons learned are not forgotten, it is recommended that applicable processes, procedures or checklists 
Proceedings - 17th Annual International Symposium, International Council on Systems Engineering, San Diego, June 24-28 2007.

be modified/updated as soon as a lessons-learned session is completed. Also, it may be possible to integrate lessons learned from the Peer Reviews.

\section{Conduct lessons-learned sessions on process improvement activities}

The Pittsburgh site has only conducted lessons-learned sessions on projects. Since the site is planning to implement the new CMMI model in all divisions, it is recommended that lessons-learned sessions be conducted on the process improvement activities conducted so far in order to better prepare for the second cycle of improvements.

\section{Evaluate people (Change Management Readiness) at all TTS sites}

It is well known that one of the main factors in the success of a major change project is the people factor (e.g. the soft issues involved in managing changes). Before launching the new CMMI process improvement project at all TTS sites and in all groups, a thorough analysis of cultural issues should be performed. This will allow the identification, mainly in other divisions, of strengths and barriers that will need to be addressed to increase the probability of success of the CMMI project.

\section{Improve the Peer Review process}

Data presented during the 2006 site visit demonstrated the utilization of a Peer Review technique. Figure 5 illustrates the types of defect found by Peer Reviews (November 2005 data).

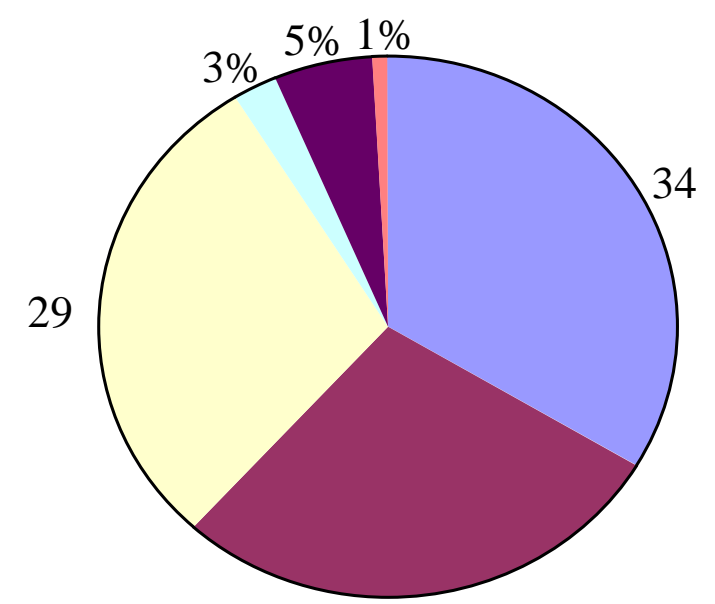

Coding Standards

Documentation

Incorrect Implementation

Requirements

Graphical User Interface

Performance

28

Figure 5 - Types of defect collected from peer reviews

Since about two thirds (i.e. $34 \%+28 \%$ ) of the defects identified are related to coding and documentation standards compliance, it is recommended that all software engineers be properly trained so that Peer Review effort will be more effective in detecting major defects (defects that could lead to failure, for example, instead of wasting expertise on finding cosmetic errors). Although only 3\% of the defects are requirements defects, it is widely known that these are very expensive to fix when detected later in the development process.

Data from NASA (Bennett 2005), as illustrated in Figure 6, show that an error introduced in the requirements phase will cost 5 times more to correct in the design phase than in the phase in which it was introduced. It will cost 10 times more to repair in the code phase, 50 times more in the test phase, 130 times more in the integration phase and 368 times more when repaired during the operational phase. 
Proceedings - 17th Annual International Symposium, International Council on Systems Engineering, San Diego, June 24-28 2007.

\section{Relative Cost to Repair}

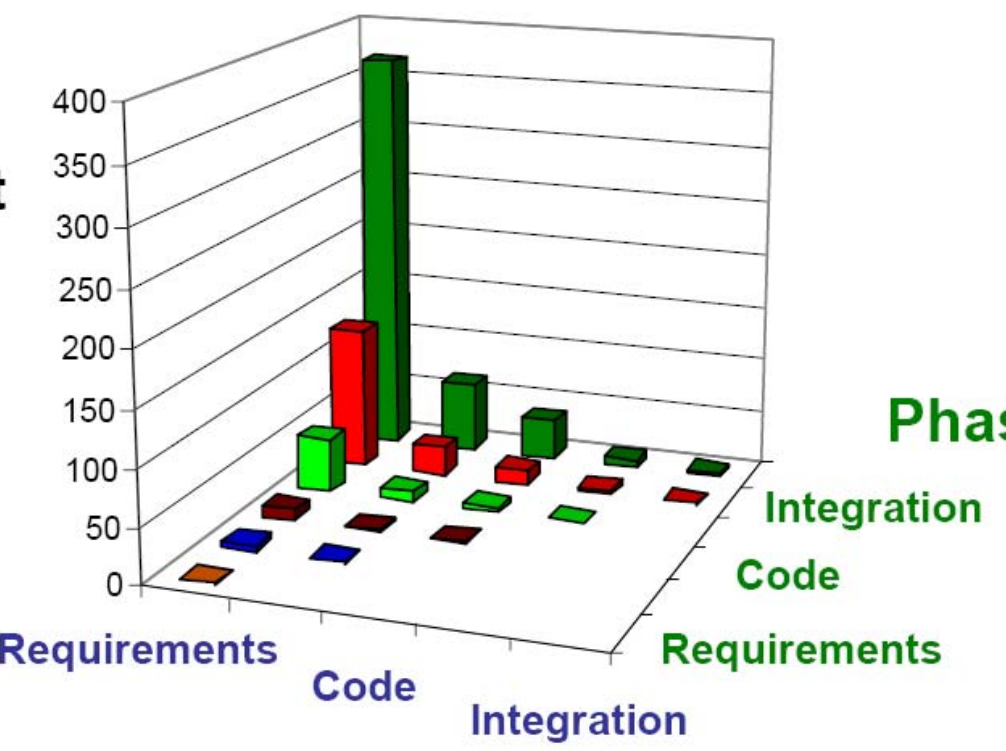

\section{Phase Defect Introduced}

Figure 6 - Relative cost of software fault propagation (Bennett 2005)

The NASA data also show, as illustrated in Figure 7 , that $74 \%$ of defects are functional faults. Functional faults are:

a. Operating fault: Omission of an operation, or an unnecessary operation.

b. Conditional fault: Incorrect condition or limit values.

c. Behavioural fault: Incorrect behaviour, i.e. not conforming to requirements.

Over $24 \%$ of these faults were interface faults. Note that only 2 percent were the result of software module coding errors.

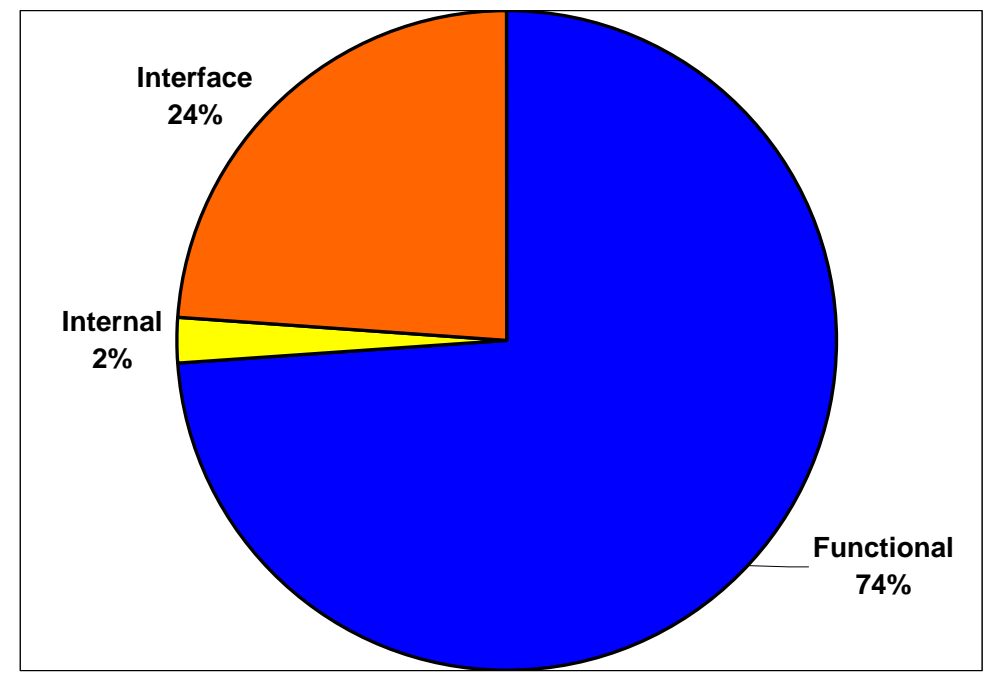

Figure 7 - Fault distribution at NASA (Bennett 2005)

In order to increase defect removal effectiveness and review efficiency of major defects, it is recommended that another type of Peer Review, called Inspection, be introduced. Inspection is a well- 
Proceedings - 17th Annual International Symposium, International Council on Systems Engineering, San Diego, June 24-28 2007.

known "best practice" technique for defect identification and removal. It was recommended that the Bombardier Transport Procedure (BES ‘Software Peer Reviews' Instruction) be adopted at the Pittsburgh site. This procedure complies with IEEE Standard 1028-Software Reviews. The adoption of the Inspection technique should be quite easy, since the Pittsburgh site is already performing a less formal type of Peer Review. The Inspection technique is in line with the six-sigma approach and the Bombardier Non Conformity Cost Reduction (NCC) program.

\section{Perform sampling Peer Reviews}

In order to evaluate the quality of a document, a sampling evaluation technique is recommended. The sampling technique allows a quick evaluation, i.e. taking approximately 30 minutes, of the number of defects per page. Using this technique, management will be in a better position to select the type of Peer Review technique best suited to the level of criticality of the document reviewed without wasting scarce resources on reviewing a document that already meets the standard of quality required.

\section{Analysis of Results}

There is a substantial improvement in the present situation over what we observed in 2003. According to our observations and supported by the statements of the interviewees, two major factors contributed to this successful implementation:

a) Senior management's real commitment
a. Personal involvement
b. Strong enforcement
c. Budget availability
d. Visible support

b) Alignment with business objectives
a. Budget availability
b. Achievements and rewards on real projects
c. Long-term positive impact
d. Process improvement for good reasons

\section{Conclusion}

This organization has moved rapidly up the CMM maturity scale, not by a desire to comply with a model, but based on defined, measurable and communicated business goals. The Pittsburgh TTS/Signalling Group's compliance with CMM Level 3 happened as a by-product of a business performance improvement effort, not the reverse.

The three major dimensions of an organization, Engineering (People), Process and Technology, are constantly put in a business context for validation and prioritization within this organization. Doing so ensures real commitment from the organization at every level, since visible return on investment is expected from any improvement initiative.

These factors, combined with the support of a strong leadership, explain the rapid performance improvements that have occurred within the organization. 
Proceedings - 17th Annual International Symposium, International Council on Systems Engineering, San Diego, June 24-28 2007.

\section{References}

(Bennett 2005) Bennett, T.L., Wennberg, P.W., Eliminating Embedded Software Defects Prior to Integration Test, Crosstalk, Journal of Defence Software Engineering, December 2005.

(Bourque 2004) Bourque, P., Belkebir, Y., Laporte, C.Y., Doucet, M., Palza, E., Coverage Analysis and Improvement of the Role Definitions of the Bombardier Software Engineering Process. Proceedings - International Conference Software \& Systems Engineering and their Applications (ICSSEA), Paris (France) 2004.

(Drolet 2004) Drolet, M., Stover, J., The Challenges in the Delivery of Automated Train Operation Systems. Presented at AsiaRail 2004 International Congress, Nov 30 - Dec 2, 2004, Hong Kong.

(Laporte 2005) Laporte, C.Y., Bourque, P., Belkebir, Y., Doucet, M., Amélioration de la définition des rôles du processus de génie logiciel de la société Bombardier Transport, Revue Génie Logiciel, Number 72, March 2005, pp 43-52.

(Laporte 1993) Laporte, C.Y., Process Improvement and the Management of Change, Proceedings: 4th IEEE Computer Society Workshop on Software Engineering Technology Transfer, Dallas, April 28-29 1993.

(Laporte 1998) Laporte, C.Y., Trudel, S. Addressing the people issues of process improvement activities at Oerlikon Aerospace. Software Process-Improvement and Practice, 4(1), pp 187.198.

(Laporte 1999) Laporte, C.Y., Trudel, S., Addressing People Issues when Developing and Implementing Engineering Processes, Crosstalk - Journal of Defence Software Engineering, November 1999.

(IEEE 1028-02) IEEE 1028-2002 Software Reviews, Institute of Electrical and Electronics Engineers, 2002.

(SEI93) CMM (SW-CMM), Software Capability Maturity Model® (SW-CMM) v1.1, CMU/SEI-93TR-025, Software Engineering Institute, Carnegie Mellon University, February 1993.

(SEI06) Software Engineering Institute. Capability Maturity Model Integration for Development (CMMi). (2006). Version 1.2, CMU/SEI-2006-TR-008. Software Engineering Institute, Carnegie Mellon University, Pittsburgh (PA).

EN50128, Railway applications -Communications, Signalling and Processing Systems - Software for Railway Control and Protection Systems, European Standard, 2001.

ISO 9001 (2000), Quality management systems - Requirements, International Organization for Standardization, Geneva, Switzerland.

ANSI/EIA-748-A-1998 (R2002), Earned Value Management Systems, American National Standard Institute/Electronic Industry Association, June 1998. 
Proceedings - 17th Annual International Symposium, International Council on Systems Engineering, San Diego, June 24-28 2007.

\section{Biographies}

Claude Y Laporte teaches graduate and undergraduate courses in software engineering. His research interests include software process improvement in small and very companies and software quality assurance. He received a Master's degree in Physics from the Université de Montréal and a Master’s degree in Applied Sciences from the École Polytechnique de Montréal. He holds a Canadian Decoration (CD). He is the editor of an ISO/IEC-JTC1 SC7 working group tasked to develop software life cycle profiles and guidelines for use in very small enterprises. He is a member of INCOSE, IEEE, PMI, and of the Professional Association of Engineers of the Province of Québec.

Mikel Doucet is responsible for the Center of Competence in Software Engineering at Bombardier Transport international leader in rail transport solutions. This Center supports together nearly 950 people and has the mandates of definition and the deployment of common process and tools, the evaluation of risks and the direct support with the projects. This Center of Competences is also responsible for the network management of exchanges between these various groups. He received a Master in Engineering Management from the Sherbrooke University in 2002. In 1991, he received a bachelor in Mechanical Engineering for the Sherbrooke University.

Denis Roy has occupied, during the last 20 years, senior management positions for Quantum Information Resources, Paramax Canada Inc. (Lockheed-Martin) and, from 1992 to 1998, he served as General Director of the Applied Software Engineering Center at CRIM. From 1998 to 2005, he was President and CEO of YORTAR Technologies Systems Inc., where he managed and conducted numerous projects related to risk management, performance improvement and systems/software engineering cost reduction within large corporations and, for Provincial and Federal Government and agencies. He is now the General Director of the Strategic Advisory Group at the Computer Research Institute of Montreal.

Marc Drolet joined Bombardier as Vice President Project Management, and subsequently as Vice President of Total Transit Systems Signalling. He is based in the Bombardier Pittsburgh office, and is responsible for the Bombardier driverless signalling for two major projects for the Madrid Metro, and is responsible for the Bombardier Kingston engineering site. He has a degree in Physics, a Master degree in Engineering and EMI/EMC, holds a Canadian Decoration (CD), and is a Certified Project Management Professional (PMP) with the Project Management Institute (PMI) organization. He is also a graduate of the Canadian Military Senior Staff College in Toronto. 